\title{
Reliable ligamentous stability and high return-to-sport rates after arthroscopic reduction and internal fixation of tibial eminence fractures
}

\author{
Patricia M. Lutz ${ }^{1}$. Stephanie Geyer ${ }^{1} \cdot$ Philipp W. Winkler $^{1} \cdot$ Markus Irger $^{1} \cdot$ Daniel P. Berthold ${ }^{1} \cdot$ Matthias J. Feucht ${ }^{1,2}$. \\ Andreas B. Imhoff ${ }^{1} \cdot$ Philipp Forkel $^{1}$
}

Received: 23 March 2021 / Accepted: 14 May 2021 / Published online: 19 May 2021

(C) The Author(s) 2021

\begin{abstract}
Purpose To investigate functional and clinical outcomes, and physical activity after arthroscopic suture fixation of tibial eminence fractures with regard to postoperative stability, range of motion (ROM), complications, and return to sports.

Methods Patients undergoing arthroscopic reduction and internal fixation (ARIF) of tibial eminence fractures using a suture fixation technique were included. Outcome was evaluated retrospectively after a minimum follow-up of 24 months using KT-1000 arthrometer measurements, clinical examination, outcome scores (Lysholm score, Tegner Activity Scale), and a questionnaire about sport activities.

Results A total of 23 patients (44\% male, $57 \%$ female) with a mean age of $25 \pm 15$ years were included. Mean follow-up was $57 \pm 25$ months. KT-1000 arthrometer measurements of anterior tibial translation revealed a mean side-to-side difference of $0.9 \pm 1.0 \mathrm{~mm}$. Clinical examination showed $100 \%$ normal or nearly normal anterior translation of the tibia. Two patients (9\%) received an ACL reconstruction due to traumatic ACL re-instability and were, therefore, considered as failures. An extension deficit concerning hyperextension occurred in $29 \%$ of patients postoperatively. Further postoperative complications occurred in $14 \%$ of patients and included postoperative stiffness with ROM limitations and secondary dislocation of a fragment. Mean postoperative Lysholm score was $89 \pm 14$. Comparing pre- and postoperative values, no significant change of the Tegner Activity Scale was observed. All patients (failures excluded) returned to high impact sports activities after ARIF. Conclusion Excellent reliable ligamentous stability and high rates of return to high impact sports can be expected after ARIF using a suture fixation technique for type II-IV tibial eminence fractures. Complications, such as limitations in ROM, commonly occur in up to $30 \%$ after ARIF. Therefore, regular follow-up examinations remain important in this usually young patient cohort.
\end{abstract}

Level of Evidence Level IV.

Keywords Tibial eminence fracture · Tibial spine · Adolescent ACL · ARIF · Suture fixation · Return to sport

Patricia M. Lutz

patricia.lutz@gmx.net

1 Department for Orthopedic Sports Medicine, Technical University Munich, Ismaninger Str. 22, 81675 Munich, Germany

2 Department of Orthopedics and Trauma Surgery, Medical Center, Faculty of Medicine, Albert-Ludwigs-University of Freiburg, Freiburg, Germany

\section{Introduction}

Avulsion fractures of the tibial eminence and subsequent acute anterior cruciate ligament (ACL) deficiency are often referred as a rare injury in the adult population as they mostly occur in children and adolescents due to their skeletal immaturity, muscle weakness, and increased elasticity of the ligaments [26, 27]. However, these injuries can generally affect all age groups and show a high association with concomitant meniscal injuries [6, 8, 10, 27]. First described by Meyers and McKeever in 1959, patients with instable type II-IV injuries [24, 25, 46] are generally indicated for surgical stabilization, regardless of their age $[5,6,10,17,40]$. 
Current literature covers several open and arthroscopic surgical approaches of internal reduction and fixation, mainly including screws or high-tensile suture devices with postoperative arthrofibrosis and secondary ACL deficiency requiring reconstruction being the most common complications [ 2 , 4-6, 10, 17, 23, 26, 31, 32, 36, 44, 45]. Recently, satisfactory patient-reported and functional outcomes in the treatment of intercondylar eminence fractures in children and adolescents with bio-absorbable nails were reported [19]. Generally, good clinical and functional outcomes have been reported after arthroscopic reduction and internal fixation (ARIF) of tibial eminence avulsion fractures, however, these studies are often limited to their small sample size $[3,5,6,10,11,17$, $18,30,31,33,36,44]$. Although a vast number of studies investigated postoperative outcomes and complications following ARIF, there remains a lack of data reporting on postoperative ligamentous stability, return to sports, and physical activity. However, this may be of clinical relevance, as this younger patient cohort in particular, often comes along with high expectations concerning postoperative level of return to sports and physical activity.

Therefore, the purpose of this retrospective study was to investigate clinical and functional outcomes, return to sports, and physical activity after ARIF of tibial eminence avulsion fractures using high-tensile suture devices in patients suffering from instable grade II-IV tibial eminence fractures. It was hypothesized that the mean difference in anterior tibial translation between the affected, injured and non-affected, healthy leg is smaller than $3 \mathrm{~mm}(\mathrm{~mm})$ measured using a validated KT-1000 arthrometer.

\section{Methods}

The study was approved by the institutional review board of the Technical University of Munich (341/20 S). All patients and their parents, if under 18-years old, gave their written informed consent to participate in this investigation.

\section{Patients}

A retrospective chart review was performed on a consecutive cohort of all patients undergoing ARIF after tibial eminence avulsion fractures at the authors' institution between July 2011 and July 2018. Patients were eligible for inclusion if noted to have unilateral ARIF following type II-IV tibial eminence avulsion fractures according to Meyers and McKeever [25] modified by Zaricznyj [46] with or without concomitant meniscus lesions as initially noted on magnet resonance imaging (MRI) and confirmed arthroscopically at the time of surgery. The Meyers and McKeever classification describes four subtypes, with type 1 being non-displaced and type 4 being a displaced multi-fragment avulsion of the tibial eminence $[25,46]$. Patients were excluded from the study if they had a history of previous surgery at the index or the contralateral, non-affected knee, and/or concomitant ligamentous injuries other than avulsion fractures of the ACL. Baseline demographic variables, including patient age and gender, were manually collected using clinical notes of all patients. Failure was defined as secondary ACL deficiency requiring reconstruction (ACL-R) after ARIF. The patient selection process is shown in Fig. 1.

\section{Radiological assessment}

Prior to surgery, all patients had undergone a thorough clinical and radiological (X-rays, MRI, and, if indicated, computed tomography (CT) scans) examination to detect tibial eminence avulsion fractures with or without concomitant meniscus lesions. To confirm the correct position of the suture and complete reduction of the fragment, standardized anterior-posterior (a.p.) and lateral radiographs were carried out postoperatively.

\section{Clinical examination}

All subjects underwent postoperative clinical examination of the knee, including previously validated KT-1000 arthrometer measurements (MEDmetric, San Diego, CA, USA) [1, 7, $9,15,34,45]$, by a knee trained orthopedic resident (P.M.L) at a minimum follow-up of 2 years. Clinical evaluation of the patient's knee joint was based on the International Knee Documentation Committee (IKDC) knee examination form $[12,13]$. Free range-of-motion (ROM) was measured using a goniometer. Clinical examination of the ligament stability included testing the laxity of the anterior and posterior cruciate ligament, as well as the medial collateral ligament (MCL) and lateral collateral ligament (LCL). Anterior tibial

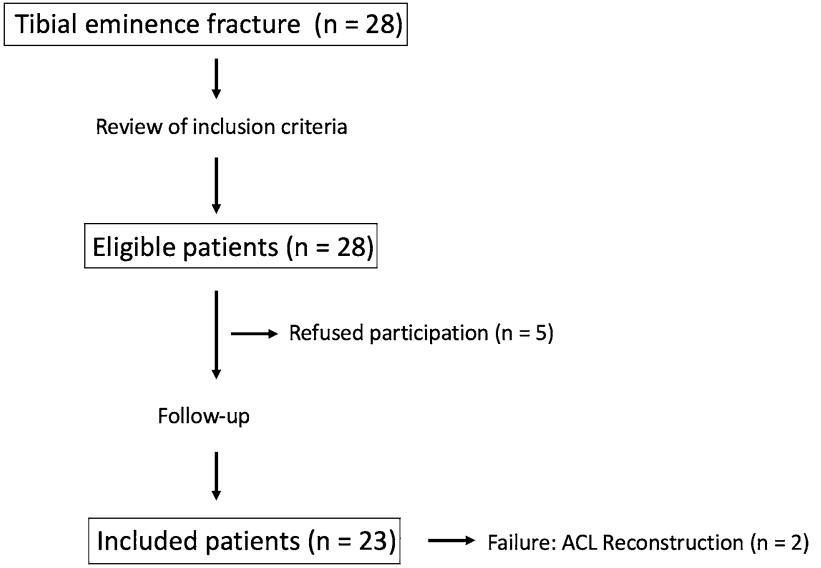

Fig. 1 Enrollment flowchart of the study. $A C L$ anterior cruciate ligament 
displacement was first evaluated using the Lachman test and quantitatively measured using the KT-1000 arthrometer. The KT-1000 arthrometer measurements were performed using a standardized $134 \mathrm{~N}$ anterior draw force at $30^{\circ}$ knee flexion and side-to-side differences were recorded in $\mathrm{mm}$. The KT-1000 arthrometer measurements were performed using the maximal manual forces and side-to-side differences were recorded in $\mathrm{mm}$. The pivot-shift test was graded as negative, $1+$ (glide), $2+$ (clunk), or $3+$ (locking) [14, 41]. All results were compared with the non-affected knee and documented. Any meniscus pathology was evaluated by joint space tenderness, the Steinmann test [39] and as initially noted on MRI and confirmed arthroscopically at time of surgery.

\section{Functional outcomes}

Patient-reported outcomes were measured using the Lysholm score and the Tegner Activity Scale at final follow-up [12, 42]. Similar to $\mathrm{Xu}$ et al. and Dung et al. a differentiation of the Lysholm score results into excellent (95-100), good (85-94), fair $(65-84)$, and poor $(<65)$ was made $[7,45]$. To provide a concise understanding of the sport activity level in this collective, patients were asked about pre- and postoperative types of sport activities, activity levels, and return-tosport activities. The subjective postoperative sports ability could be rated on an ordinal scale ("improved", "equal to preoperative state", or "deteriorated") and reasons for a subjective deterioration in physical activity were investigated ("due to the operated knee", "due to other physical problems not related to the operated knee", or "due to non-physical personal reasons").

\section{Surgical technique}

All surgical procedures were performed by fellowshiptrained senior orthopedic surgeons (P.F. and A.B.I).

In all patients, ARIF of the avulsion fracture was performed (Fig. 2). Routine diagnostic arthroscopy was performed through a high anterolateral portal. In case of any concomitant meniscus lesions, meniscus suture systems (Arthrex Inc, Naples, FL, USA) were used or partial resection of the meniscus was performed prior to ARIF if indicated. Subsequently, the instable fractured tibial eminence fragment was exposed and carefully debrided. The transverse ligament was visualized and the tibial fracture site was debrided. Then a curved $90^{\circ}$ SutureLasso (Arthrex Inc., Naples, FL, USA) was passed through the distal ACL from posteromedial in an anterolateral direction through an anteromedial portal. A FiberWire Number 2 (Arthrex Inc, Naples, FL, USA) was shuttled through the ACL. A second suture was shuttled through the anterior part of ACL. Two transtibial K-wires were then placed mid into the instable eminence fragment to securely fix the fragment, and were then subsequently overdrilled. Then, the suture was shuttled through the drill holes and by pulling on the free ends of the FiberWire sutures (Arthrex Inc, Naples, FL, USA), the fractured eminence fragment was then securely repositioned into the fracture site. Catching of the transverse ligament was
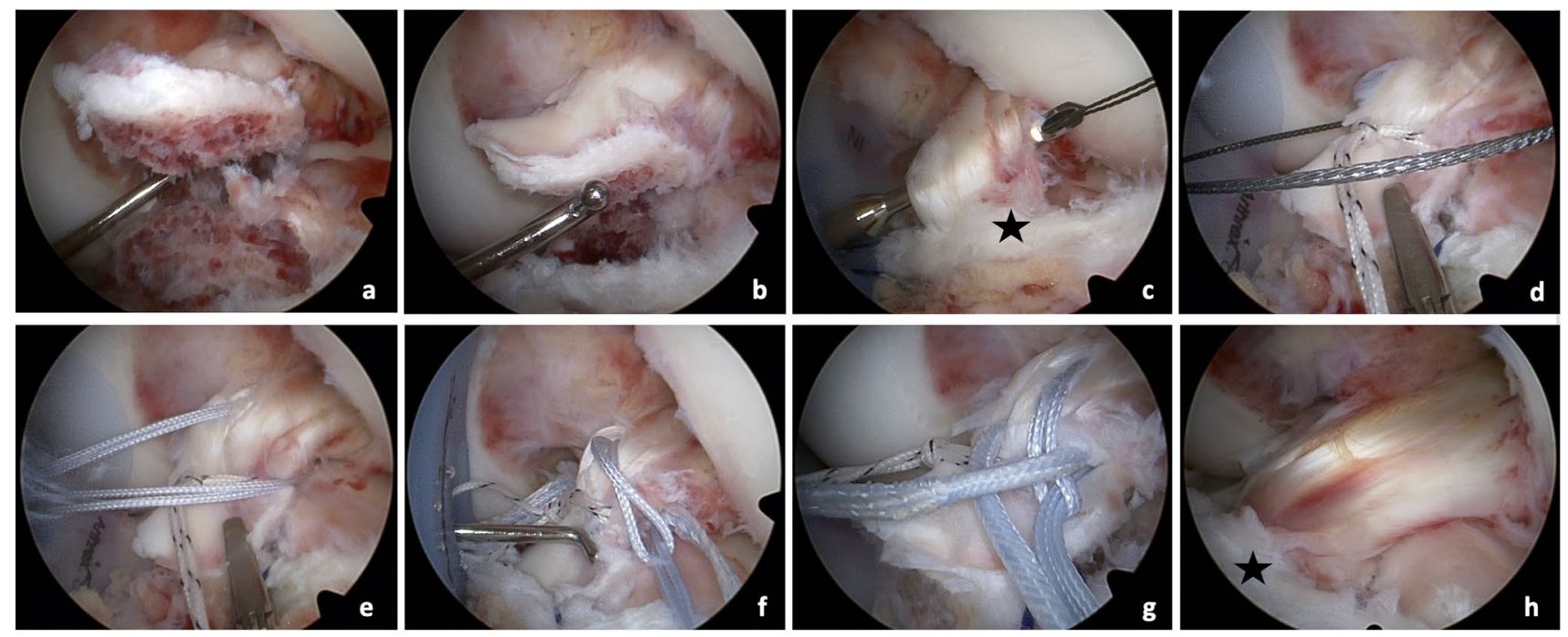

Fig. 2 ARIF of tibial eminence fracture. a confirmation of tibial eminence fracture; $\mathbf{b}$ exposure of the instable fractured tibial eminence fragment; c a SutureLasso (Arthrex Inc., Naples, FL, USA) is passed through the distal ACL from posteromedial in an anterolateral direction; d a FiberWire Number 2 (Arthrex Inc., Naples, FL, USA) is shuttled through the ACL; e a second suture is shuttled through the anterior part of ACL; $\mathbf{f}-\mathbf{g}$, ARIF of the fractured tibial eminence; $\mathbf{h}$, reposition of the fractured fragment with an individual adaptation of tension and stability of the native ACL; Black star marks transverse ligament. ACL anterior cruciate ligament, ARIF arthroscopic reduction and internal fixation 
avoided. For tibial fixation, an extracortical suture plate was used. To confirm the correct position of the suture and complete reduction of the fragment, standardized a.p. and lateral radiographs were carried out intra-operatively (Fig. 3).

\section{Rehabilitation}

The postoperative protocol consisted of 6 weeks of partial weight-bearing $(20 \mathrm{~kg})$ on crutches with limitations to active and passive ROM (Extension/Flexion $0^{\circ} / 0^{\circ} / 90^{\circ}$ ) [32]. A knee brace (Medi M4, Medi Bayreuth, Germany) was provided for at least 12 weeks. When performing additional meniscal repair, $\mathrm{ROM}$ was restricted from $0^{\circ}$ to $60^{\circ}$ of knee flexion for the first 6 weeks to protect the construct. Returnto-sport-specific training was allowed after 3 months and full return to contact and/or pivoting sports activities after at least 6 months postoperatively.

\section{Statistical analysis}

All statistical analyses were performed using SPSS software Version 25 (IBM, Armonk, New York, USA) and Microsoft Excel Version 2019 (Microsoft, Redmond, Washington, USA). For all statistical tests, $p$ values less than 0.05 were considered as statistically significant. Kolmogorov-Smirnov univariate normality test was used for continuous variables to confirm data normality. Descriptive statistics were presented as mean \pm standard deviation (SD) for all continuous variables. Frequencies (n, \%) were used to obtain descriptive statistics for all categorical variables. The one-sample $\mathrm{t}$ test was applied to test for the null hypothesis (true mean difference equals $3 \mathrm{~mm}$ ). The Wilcoxon test was conducted to test for differences in Tegner Activity Score between preoperative and postoperative measurements.

In the study of Pandey et al. [31], a mean side-to-side difference of $0.85 \mathrm{~mm}$ and a standard deviation (SD) of $0.90 \mathrm{~mm}$ were observed in KT-1000 measurements. Even under a conservative assumption of a mean difference of $1.5 \mathrm{~mm}$ and a SD of $1.5 \mathrm{~mm}$, with a sample size of 21 patients (failures excluded), the power analysis revealed a power of $90 \%$ to reject the null hypothesis in a one-sample $t$ test (significance level of 5\%, two-sided test).

\section{Results}

In total, 28 patients underwent ARIF of tibial eminence avulsion fractures in the authors' institution between July 2011 and July 2018. Of these 28 patients, two patients received an ACL-R due to traumatic ACL re-instability and were, therefore, considered as failures; Five patients were not willing to participate, leaving 21 patients examined in the present study. Patient demographics of the total study group are shown in Table 1. Concomitant meniscal injuries were found in eight patients (35\%).

\section{Clinical presentation and outcome}

After a mean follow-up of $57 \pm 25$ months (28-103), clinical examination showed a $1+$ Lachman in two patients and a $1+$ pivot-shift test in three patients. ROM measurement using the goniometer showed an extension deficit in six patients concerning hyperextension. No flexion deficit occurred in the study group. Mean side-to-side difference
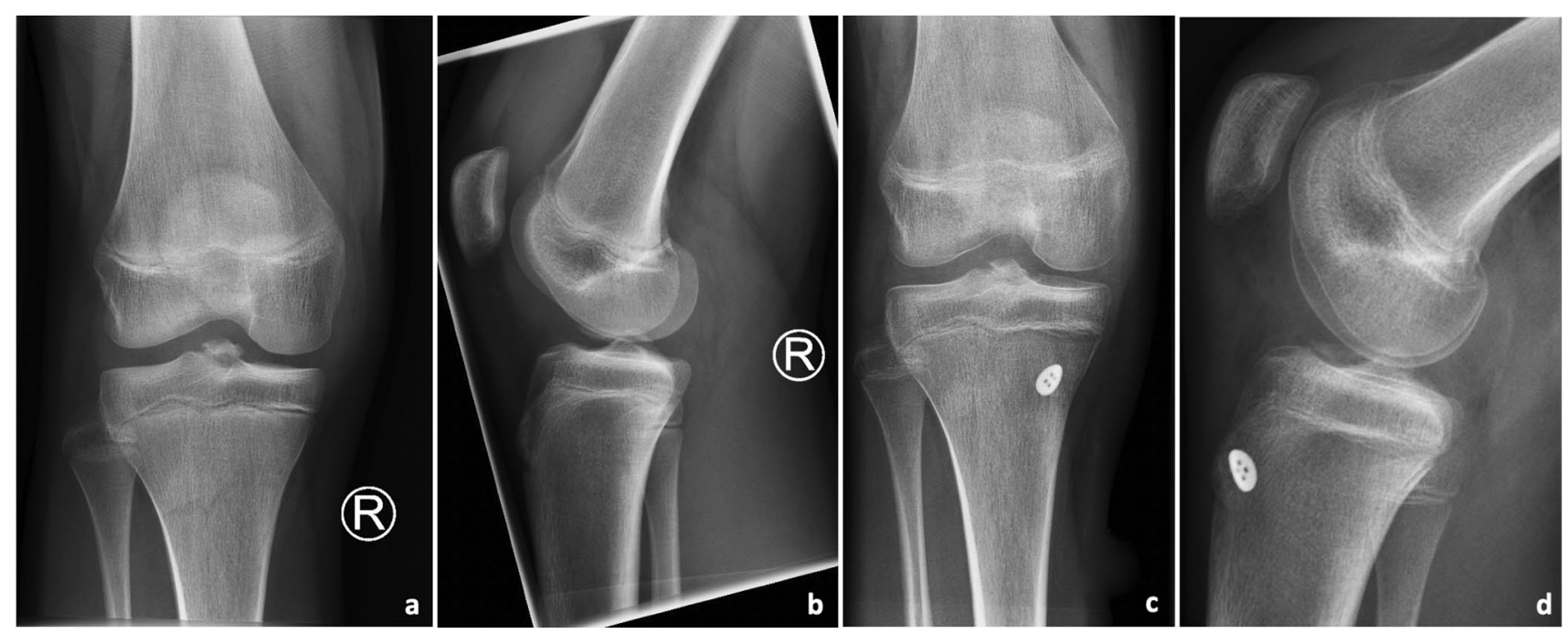

Fig. 3 Standardized anterior-posterior and lateral radiographs in a right knee showing a tibial eminence avulsion fracture preoperatively $(\mathbf{a}-\mathbf{b})$ and on the first postoperative day after ARIF (c-d). For tibial fixation, an extracortical suture plate was used (c-d). ARIF arthroscopic reduction and internal fixation 
Table 1 Patient demographics of the total study group

\begin{tabular}{ll}
\hline Number of patients, $n$ & 23 \\
\hline Follow-up (months) & $57.1 \pm 24.7(28-103)$ \\
Age (years) at surgery & $24.5 \pm 15.4(6-52)$ \\
Sex, $n(\%)$ & \\
Male & $10(43.5 \%)$ \\
Female & $13(56.5 \%)$ \\
BMI (kg/m $\left.{ }^{2}\right)$ & $23.0 \pm 4.7(16.0-37.6)$ \\
Laterality, $n(\%)$ & \\
Right & $10(43.5 \%)$ \\
Left & $13(56.5 \%)$ \\
MM type, $n(\%)$ & \\
Type II & $10(43.5 \%)$ \\
Type III & $12(52.2 \%)$ \\
Type IV & $1(4.3 \%)$ \\
Mechanism of injury, $n(\%)$ & \\
Skiing accident & $15(65.2 \%)$ \\
Hoverboard accident & $2(8.7 \%)$ \\
Bike accident & $2(8.7 \%)$ \\
Sports accident (basketball, soccer) & $4(17.4 \%)$ \\
Concomitant procedures, $n(\%)$ & $15(65.2 \%)$ \\
None & $1(4.3 \%)$ \\
Partial resection of meniscus & $7(30.4 \%)$ \\
Meniscal repair & \\
\hline
\end{tabular}

Continuous variables are shown as mean \pm standard deviation (range), categorical variables are shown as percentages

$B M I$ body mass index, MM type modified Meyers and McKeever classification type

for anterior translation of the tibia, measured with the KT-1000 arthrometer, was $0.9 \pm 1.0 \mathrm{~mm}$ (95\% confidence interval (CI) $0.4-1.4 ; p<0.001$ ). Results of clinical examination are summarized in Table 2.

Table 2 Clinical results of the examined study group

\begin{tabular}{ll}
\hline Clinical results & Study group* \\
\hline KT-1000, side-to-side difference $(\mathrm{mm})$ & $0.9 \pm 1.0(-1.6$ to 2.3$)$ \\
Lachman test, $n(\%)$ & $19(90.5 \%)$ \\
Negative & $2(9.5 \%)$ \\
$1+$ & \\
Pivot-shift test, $n(\%)$ & $18(85.7 \%)$ \\
Negative & $3(14.3 \%)$ \\
$1+$ & \\
\hline
\end{tabular}

Continuous variables are shown as mean \pm standard deviation (range), categorical variables are shown as percentages. ${ }^{*} n=21$ patients;

$K T-1000$ manual maximum displacement test, $S D$ standard deviation, mm millimeter

\section{Lysholm score and return-to-sports}

The descriptive data for postoperative Lysholm score, pre-operative and postoperative Tegner Activity Scale, return-to-sport activities, and physical activity are summarized in Table 3. At final follow-up, $100 \%$ of patients were involved in sport activities. In general, frequency of sport activities was $2.5 \pm 1.5$ sessions per week preoperatively and $2.4 \pm 1.7$ sessions per week postoperatively (n.s.). In the patient subgroup that reported a reduced frequency of sports activity postoperatively, two patients $(10 \%)$ attributed the deterioration to the operated knee, while five patients (24\%) accredited it to non-physical personal reasons.

Postoperatively, the most commonly performed sport activities were cycling (81\%), swimming (67\%), skiing (67\%), hiking (52\%), and fitness (29\%) (Table 4).

\section{Complications}

Two patients suffered from postoperative stiffness with ROM limitations due to postoperative arthrofibrosis. A second look arthroscopy with subsequent arthrolysis was necessary to regain full ROM after 5 and 10 months, respectively. One patient suffered from secondary dislocation of the fractured fragment and removal of the fragment was necessary 5 days after the initial operation.

Table 3 Physical activity and clinical outcome scores of the examined study group

\begin{tabular}{ll}
\hline & Study group* \\
\hline Lysholm score & $88.9 \pm 14.0(58-100)$ \\
Excellent, $n(\%)$ & $12(57.1 \%)$ \\
Good, $n(\%)$ & $3(14.3 \%)$ \\
Fair, $n(\%)$ & $5(23.8 \%)$ \\
Poor, $n(\%)$ & $1(4.8 \%)$ \\
TEGNER preoperative & $6^{+}(\text {range }, 1-10)^{\S}$ \\
TEGNER postoperative & $6^{+}(\text {range, } 1-10)^{\S}$ \\
Return-to-sport activities, $n(\%)$ & \\
Yes & $21(100 \%)$ \\
Change in postoperative sports ability & \\
$\quad$ No change, $n(\%)$ & $15(71.4 \%)$ \\
$\quad$ Improved, $n(\%)$ & $4(19.0 \%)$ \\
Deteriorated, $n(\%)$ & $2(9.5 \%)$ \\
\hline
\end{tabular}

Continuous variables are shown as mean \pm standard deviation (range), categorical variables are shown as percentages. $*_{n}=21$ patients; ${ }^{+}$ Values are median; ${ }^{\S}$ no significant difference between pre- and postoperative TEGNER $(p=0.102)$;

TEGNER tegner activity scale 
Table 4 Details of sport activity after ARIF of tibial eminence fractures

\begin{tabular}{lll}
\hline Type of sport & Study group* & \\
\hline & Preinjury & Follow-up \\
Skiing & $17(81 \%)$ & $14(67 \%)$ \\
Cycling & $15(71 \%)$ & $17(81 \%)$ \\
Swimming & $13(62 \%)$ & $14(67 \%)$ \\
Hiking & $12(57 \%)$ & $11(52 \%)$ \\
Jogging & $6(29 \%)$ & $4(19 \%)$ \\
Soccer & $6(29 \%)$ & $5(24 \%)$ \\
Fitness & $5(24 \%)$ & $6(29 \%)$ \\
Tennis & $3(14 \%)$ & $4(19 \%)$ \\
Ice Hockey & $2(10 \%)$ & $2(10 \%)$ \\
Cross-country skiing & $2(10 \%)$ & $3(14 \%)$ \\
Dancing & $2(10 \%)$ & $1(5 \%)$ \\
\hline
\end{tabular}

Values are expressed as number of patients (percentage of patients) who performed the sport activities before the injury and at follow-up. Multiple answers were possible. $*_{n}=21$ patients

$A R I F$ arthroscopic reduction and internal fixation

\section{Failures}

Two younger patients (one male, one female) with a mean age of $13 \pm 1$ years (12-14), suffered from traumatic ACL re-instability after ARIF and required ACL-R. The causing mechanisms of re-injury were skiing and bike accidents.

\section{Discussion}

The most important finding of the present study was that there were no side-to-side differences in the KT-1000 measurements between the injured and non-injured leg in patients after ARIF of a tibial eminence avulsion fracture after a mean follow-up of $57 \pm 25$ months. In addition, those findings were confirmed by the clinical examinations showing similar results with $100 \%$ Lachman negative or $1+$ when manually tested. As such, a 100\% return-to-sport activities were achieved with no change in postoperative Tegner Activity Scale and no significant reduction of postoperative frequency of sport activities was observed after isolated ARIF of tibial eminence fractures. Of interest, most tibial eminence avulsion fractures were noted to occur due to highenergy pivoting sport activities.

To date, only few authors assessed ligamentous stability using the KT-1000 after ARIF of tibial eminence avulsion fractures, which are mostly limited to small patient cohorts $[3,7,11,17,31,33,45]$. Generally, a side-to-side difference less than $3 \mathrm{~mm}$ indicates that native ligamentous stability may be restored $[1,38]$. Similar to the results of 26 patients after an all-arthroscopic suture pull-out fixation of displaced tibial spine avulsion fractures reported by Pandey et al.[31], small side-to-side differences could be found in the present study $(0.9 \pm 0.9$ versus $0.9 \pm 1.0)$. Interestingly, Seon et al. used instrumented stress radiography to report an anterior tibial translation of under $5 \mathrm{~mm}$ in over $90 \%$ of their patients after ARIF in suture technique [36]. Coyle et al. described patients after tibial eminence fractures having almost $5 \mathrm{~mm}$ of anterior tibial translation [6]. Similar to current literature [3, 18, 19, 33], good-to-excellent objective knee stability was reported in the present study. When assessing a.p. instability clinically by performing the Lachman and Pivot-shift test, approximately $85 \%$ of patients in this cohort showed normal laxity.

Overall, outcomes scores such as Lysholm score and Tegner Activity Scale have been considered common outcome parameters of studies evaluating surgical ACL treatment. Comparable to the results of this study $(88.9 \pm 14.0)$, the Lysholm score outcomes were high in multiple studies after ARIF of tibial eminence fractures [3, 7, 10, 18, 31, 36, 45]. Similar to the results of Xu et al. [45], about $70 \%$ of patients reached excellent or good results in the Lysholm score in the present study. Since ACL-R results in high return-tosport rates with clear limitations in terms of postoperative sports activity level [16, 20-22], physical activity remains an important outcome parameter after ARIF of tibial eminence fractures. To date, only Callanan et al. investigated on sport activities and return-to-sport following ARIF after tibial eminence avulsion fractures [5]. They indicated that postoperatively, their patient cohort returned to high impact sport activities, such as football, soccer, skiing, skating, and horse riding [5]. Of interest, Hirschmann et al. and Perugia and colleagues mentioned that preinjury sports activity level was reached by all patients without further specifications $[11,33]$. Similarly $[10,11,18]$, the median Tegner Activity Scale, which did not change postoperatively, was high in the present patient cohort, indicating no change in postoperative physical activity levels. Nevertheless, in the present study, two subjects claimed that physical activity deteriorated postoperatively. Another important finding was that return to high impact sport activities, such as skiing, cycling, hiking, and fitness was high after isolated ARIF of tibial eminence fractures (failures excluded). Subsequently, a high returnto-sports rate may be expected in this mostly young, active, and challenging patient cohort.

In consideration of the clinical and functional findings in this study, immediate refixation of the tibial eminence using the presented technique should be considered in these patients, as future ACL-R may be avoided. Additionally, when compared to adults, the outcome after ACL-R was demonstrated to be worse in children and adolescents $[28,35]$. As such, the presented technique has multiple advantages when compared to conventional ACL-R: the minimal invasive approach allows for fast restoration of native biomechanical properties of the ACL in skeletally 
immature patients. Even if the reported revision and postoperative complication rate was noted to be high, this procedure does not destroy the path, even if the refixation of the unstable fragment fails. In addition, reposition of the fractured eminence fragment can be adjusted manually and individually to each patient, resulting in individual adaptation of tension and stability of the native ACL. Since mostly younger patients are affected of this type of injury, it may be of clinical relevance, as any muscular dysbalance due to harvesting of hamstring or quadriceps tendons may be avoided. Furthermore, it was recently reported that ACL-R in children and adolescents can lead to growth disturbances evolving throughout the entire process of remaining growth $[29,35]$.

Unfortunately, secondary ACL-R was required in two patients after ARIF in this cohort. This number is comparable to previous data published by Mitchell et al., who reported that $12 \%$ of patients required future ACL-R secondary to a delayed ACL rupture following ARIF of a tibial eminence fracture [26]. Possible explanations include elongation of ACL fibers at the moment of trauma followed by knee instability and a higher risk of ACL injuries secondarily $[6,37]$.

Interestingly, concomitant meniscal injuries occurred in eight patients (35\%), which is similar to a recent study by Feucht et al., who demonstrated a $37 \%$ incidence of meniscal injury at the time of a tibial eminence fracture [8]. This high number of concomitant meniscal injuries in patients with tibial eminence avulsion fracture may occur secondary to higher-energy impaction of the tibia plateau against the femoral condyle during the high-energy pivoting injury mechanism. In addition, these finding could be attributable to anatomic proximity of the anterior root of the lateral meniscus as well as to a change in athletic activities with an increasing number of pivot-type injuries lately [8, 27]. However, similar to previous research after ACL-R [22], the results of the present study led to the assumption that additional meniscal lesions did not have an effect on postoperative stability or return-to-sport activity following ARIF.

When reviewing current literature, postoperative stiffness due to arthrofibrosis or mechanical impingement of displaced bony fragments is a common complication after ARIF of tibial eminence fractures [30-32, 43, 44]. According to a systematic review of Gans et al. [10], loss of ROM after tibial eminence fractures can be expected in up to $28 \%$. Furthermore, the authors described existing knee laxity in up to $43 \%$ after ARIF [10]. Similar to their results, loss of ROM was evident in $29 \%$ of examined patients in the present study. However, only hyperextension was affected in this patient cohort, indicating that an extension of $0^{\circ}$ could be achieved in all patients (extension/flexion $0 \% 0^{\circ} / \mathrm{x}^{\circ}$ ). In contrast to the results of Gans et al. [10], postoperative knee laxity was $100 \%$ normal or nearly normal.
The presented study has several limitations. First, since the retrospective study design inherently limits scientific objectivity and no control group was available, selection bias may have influenced the results. Second, the sample size was small, however, as these injuries remain a rare condition, the sample size is similar to previously published series. However, the statistical power of the present study was 0.9 . Third, concomitant meniscal injuries were not excluded from this study may influencing the presented findings. However, according to previous research, meniscal lesions were shown to have no effect on return-to-sport activity following ACL-R [22]. Still, combined procedures may induce performance bias. Fourth, the pivot-shift test is subjective and depends on the experience of the investigator. Furthermore, the final average follow-up of 57 months might not be sufficient to evaluate the long-term functional and clinical outcomes after ARIF of tibial eminence fractures.

\section{Conclusion}

Excellent Reliable ligamentous stability and high rates of return to high impact sports can be expected after ARIF using a suture fixation technique for type II-IV tibial eminence fractures. Complications, such as limitations in ROM, commonly occur in up to $30 \%$ after ARIF. Therefore, regular follow-up examinations remain important in this usually young patient cohort.

Acknowledgements The research was performed at the Department for Orthopaedic Sports Medicine, Technical University Munich, Germany.

Author contributions PF and PML designed the study. PML, SG, PWW and MI collected data. PML performed the statistical analysis and wrote the manuscript. DPB and MJF helped to design the study, assisted with statistical analysis and data interpretation, and critically reviewed the manuscript. ABI conceived of the study, helped with data interpretation and critically reviewed the manuscript. All authors read and approved the final manuscript.

Funding Open Access funding enabled and organized by Projekt DEAL. No funding was received.

\section{Declarations}

Conflict of interest Andreas B. Imhoff is a consultant for Arthrosurface and Medi Bayreuth and receives royalties from Arthrex and Arthrosurface. Philipp Forkel gets paid for lectures for Arthrex. All other authors declare that they have no conflict of interest related to this study.

Ethical approval Ethical approval was obtained from the Ethics Committee of the technical University Munich. The study was approved by the institutional review board of the Technical University of Munich (341/20 S). All procedures performed were in accordance with the ethical standards of the institutional and/or national research committee 
and with the 1964 Declaration of Helsinki and its later amendments or comparable ethical standards.

Informed consent All subjects gave their written informed consent to participate in this investigation.

Open Access This article is licensed under a Creative Commons Attribution 4.0 International License, which permits use, sharing, adaptation, distribution and reproduction in any medium or format, as long as you give appropriate credit to the original author(s) and the source, provide a link to the Creative Commons licence, and indicate if changes were made. The images or other third party material in this article are included in the article's Creative Commons licence, unless indicated otherwise in a credit line to the material. If material is not included in the article's Creative Commons licence and your intended use is not permitted by statutory regulation or exceeds the permitted use, you will need to obtain permission directly from the copyright holder. To view a copy of this licence, visit http://creativecommons.org/licenses/by/4.0/.

\section{References}

1. Achtnich A, Herbst E, Forkel P, Metzlaff S, Sprenker F, Imhoff $A B$ et al (2016) Acute proximal anterior cruciate ligament tears: outcomes after arthroscopic suture anchor repair versus anatomic single-bundle reconstruction. Arthroscopy 32:2562-2569

2. Ahn JH, Lee YS, Lee DH, Ha HC (2008) Arthroscopic physeal sparing all inside repair of the tibial avulsion fracture in the anterior cruciate ligament: technical note. Arch Orthop Trauma Surg 128:1309-1312

3. Ahn JH, Yoo JC (2005) Clinical outcome of arthroscopic reduction and suture for displaced acute and chronic tibial spine fractures. Knee Surg Sports Traumatol Arthrosc 13:116-121

4. Bram JT, Aoyama JT, Mistovich RJ, Ellis HB Jr, Schmale GA, Yen YM et al (2020) Four risk factors for arthrofibrosis in tibial spine fractures: a national 10-site multicenter study. Am J Sports Med. https://doi.org/10.1177/0363546520951192363546520 951192

5. Callanan M, Allen J, Flutie B, Tepolt F, Miller PE, Kramer D et al (2019) Suture versus screw fixation of tibial spine fractures in children and adolescents: a comparative study. Orthop J Sports Med 7:2325967119881961

6. Coyle C, Jagernauth S, Ramachandran M (2014) Tibial eminence fractures in the paediatric population: a systematic review. J Child Orthop 8:149-159

7. Dung TT, Du HG, Long NH, Son LM, Thanh DX, Son DN et al (2019) Arthroscopic fixation of ACL avulsion fracture in the Saint Paul Hospital: a review of treatment outcomes. Eur J Orthop Surg Traumatol 29:1485-1491

8. Feucht MJ, Brucker PU, Camathias C, Frosch KH, Hirschmann MT, Lorenz S et al (2017) Meniscal injuries in children and adolescents undergoing surgical treatment for tibial eminence fractures. Knee Surg Sports Traumatol Arthrosc 25:445-453

9. Forster IW, Warren-Smith CD, Tew M (1989) Is the KT1000 knee ligament arthrometer reliable? J Bone Joint Surg Br 71:843-847

10. Gans I, Baldwin KD, Ganley TJ (2014) Treatment and management outcomes of tibial eminence fractures in pediatric patients: a systematic review. Am J Sports Med 42:1743-1750

11. Hirschmann MT, Mayer RR, Kentsch A, Friederich NF (2009) Physeal sparing arthroscopic fixation of displaced tibial eminence fractures: a new surgical technique. Knee Surg Sports Traumatol Arthrosc 17:741-747
12. IKDC (2000) Formblätter International Knee Documentation Committee. https://www.sportsmed.org/AOSSMIMIS/membe rs/downloads/research/IKDCGerman.pdf.

13. Irrgang JJ, Anderson AF, Boland AL, Harner CD, Kurosaka M, Neyret $P$ et al (2001) Development and validation of the international knee documentation committee subjective knee form. Am J Sports Med 29:600-613

14. Jakob RP, Stäubli HU, Deland JT (1987) Grading the pivot shift. Objective tests with implications for treatment. J Bone Joint Surg Br 69:294-299

15. Jonsson H, Kärrholm J, Elmqvist LG (1993) Laxity after cruciate ligament injury in 94 knees. The KT-1000 arthrometer versus roentgen stereophotogrammetry. Acta Orthop Scand 64:567-570

16. Kitaguchi T, Tanaka Y, Takeshita S, Tsujimoto N, Kita K, Amano $\mathrm{H}$ et al (2020) Importance of functional performance and psychological readiness for return to preinjury level of sports 1 year after ACL reconstruction in competitive athletes. Knee Surg Sports Traumatol Arthrosc 28:2203-2212

17. Kocher MS, Foreman ES, Micheli LJ (2003) Laxity and functional outcome after arthroscopic reduction and internal fixation of displaced tibial spine fractures in children. Arthroscopy 19:1085-1090

18. Koukoulias NE, Germanou E, Lola D, Papavasiliou AV, Papastergiou SG (2012) Clinical outcome of arthroscopic suture fixation for tibial eminence fractures in adults. Arthroscopy 28:1472-1480

19. Kristinsson J, Elsoe R, Jensen HP, Larsen P (2021) Satisfactory outcome following arthroscopic fixation of tibial intercondylar eminence fractures in children and adolescents using bioabsorbable nails. Arch Orthop Trauma Surg. https://doi.org/10.1007/ s00402-021-03860-w

20. Legnani C, Peretti GM, Del Re M, Borgo E, Ventura A (2019) Return to sports and re-rupture rate following anterior cruciate ligament reconstruction in amateur sportsman: long-term outcomes. J Sports Med Phys Fitness 59:1902-1907

21. Lindanger L, Strand T, Mølster AO, Solheim E, Inderhaug E (2019) Return to play and long-term participation in pivoting sports after anterior cruciate ligament reconstruction. Am J Sports Med 47:3339-3346

22. Mardani-Kivi M, Azari Z, Hasannejad F (2020) Return to sport activity after anterior cruciate ligament reconstruction: a 6-10 years follow-up. J Clin Orthop Trauma 11:S319-s325

23. May JH, Levy BA, Guse D, Shah J, Stuart MJ, Dahm DL (2011) ACL tibial spine avulsion: mid-term outcomes and rehabilitation. Orthopedics 34:89

24. Meyers MH, McKeever FM (1970) Fracture of the intercondylar eminence of the tibia. J Bone Joint Surg Am 52:1677-1684

25. Meyers MH, McKeever FM (1959) Fracture of the intercondylar eminence of the tibia. J Bone Joint Surg Am 41:209-222

26. Mitchell JJ, Mayo MH, Axibal DP, Kasch AR, Fader RR, Chadayammuri V et al (2016) Delayed anterior cruciate ligament reconstruction in young patients with previous anterior tibial spine fractures. Am J Sports Med 44:2047-2056

27. Mitchell JJ, Sjostrom R, Mansour AA, Irion B, Hotchkiss M, Terhune EB et al (2015) Incidence of meniscal injury and chondral pathology in anterior tibial spine fractures of children. J Pediatr Orthop 35:130-135

28. Moksnes H, Engebretsen L, Risberg MA (2012) The current evidence for treatment of ACL injuries in children is low: a systematic review. J Bone Joint Surg Am 94:1112-1119

29. Moksnes H, Engebretsen L, Seil R (2016) The ESSKA paediatric anterior cruciate ligament monitoring initiative. Knee Surg Sports Traumatol Arthrosc 24:680-687

30. Osti L, Buda M, Soldati F, Del Buono A, Osti R, Maffulli N (2016) Arthroscopic treatment of tibial eminence fracture: a systematic review of different fixation methods. Br Med Bull 118:73-90 
31. Pandey V, Khanna V, Madi S, Tripathi A, Acharya K (2017) Clinical outcome of primary medial collateral ligament-posteromedial corner repair with or without staged anterior cruciate ligament reconstruction. Injury 48:1236-1242

32. Patel NM, Park MJ, Sampson NR, Ganley TJ (2012) Tibial eminence fractures in children: earlier posttreatment mobilization results in improved outcomes. J Pediatr Orthop 32:139-144

33. Perugia D, Basiglini L, Vadalà A, Ferretti A (2009) Clinical and radiological results of arthroscopically treated tibial spine fractures in childhood. Int Orthop 33:243-248

34. Pugh L, Mascarenhas R, Arneja S, Chin PY, Leith JM (2009) Current concepts in instrumented knee-laxity testing. Am J Sports Med 37:199-210

35. Seil R, Cucchi D, Ninulescu C, Dor J, Mouton C (2019) Anatomic anterior cruciate ligament reconstruction for adolescent patients with open physis. Ann Joint https://doi.org/10.21037/aoj.2019.06. 02

36. Seon JK, Park SJ, Lee KB, Gadikota HR, Kozanek M, Oh LS et al (2009) A clinical comparison of screw and suture fixation of anterior cruciate ligament tibial avulsion fractures. Am J Sports Med 37:2334-2339

37. Smith JB (1984) Knee instability after fractures of the intercondylar eminence of the tibia. J Pediatr Orthop 4:462-464

38. Song GY, Zhang H, Zhang J, Zhang ZJ, Zheng T, Feng H (2020) Excessive preoperative anterior tibial subluxation in extension is associated with inferior knee stability after anatomic anterior cruciate ligament reconstruction. Am J Sports Med 48:573-580

39. Steinmann F (1929) Referat über Meniskusverletzungen Schweiz. Med Wochenschr 10:1355-1356
40. Strauss EJ, Kaplan DJ, Weinberg ME, Egol J, Jazrawi LM (2018) Arthroscopic management of tibial spine avulsion fractures: principles and techniques. J Am Acad Orthop Surg 26:360-367

41. Tanaka M, Vyas D, Moloney G, Bedi A, Pearle AD, Musahl V (2012) What does it take to have a high-grade pivot shift? Knee Surg Sports Traumatol Arthrosc 20:737-742

42. Tegner Y, Lysholm J (1985) Rating systems in the evaluation of knee ligament injuries. Clin Orthop Relat Res 198:43-49

43. Vander Have KL, Ganley TJ, Kocher MS, Price CT, Herrera-Soto JA (2010) Arthrofibrosis after surgical fixation of tibial eminence fractures in children and adolescents. Am J Sports Med 38:298-301

44. Watts CD, Larson AN, Milbrandt TA (2016) Open versus arthroscopic reduction for tibial eminence fracture fixation in children. J Pediatr Orthop 36:437-439

45. Xu X, Liu Z, Wen H, Pan X (2017) Arthroscopic fixation of pediatric tibial eminence fractures using suture anchors: a mid-term follow-up. Arch Orthop Trauma Surg 137:1409-1416

46. Zaricznyj B (1977) Avulsion fracture of the tibial eminence: treatment by open reduction and pinning. J Bone Joint Surg Am 59:1111-1114

Publisher's Note Springer Nature remains neutral with regard to jurisdictional claims in published maps and institutional affiliations. 